\title{
ANÁLISE AMBIENTAL DO DEPÓSITO DE RESÍDUOS SÓLIDOS LOCALIZADO NA CIDADE DE CAICÓ/RN
}

\author{
Flávia Luana Dantas ${ }^{(a)}$, Marco Tulio Mendonça Diniz ${ }^{(b)}$, Raiane Islane Araújo de Souza ${ }^{(c)}$, \\ Jucielho Pedro da Silva ${ }^{(\mathrm{d})}$
}

(a) Departamento de Geografia/Centro de Ensino Superior do Serído, Universidade Federal do Rio Grande do Norte, flavia.dantas@outlook.com

(b)Departamento de Geografia/Centro de Ensino Superior do Seridó, Universidade Federal do Rio Grande do Norte, tuliogeografia@gmail.com

(c) Departamento de Geografia/Centro de Ensino Superior do Seridó, Universidade Federal do Rio Grande do Norte, raianesouza.93@outlook.com

(d)Departamento de Geografia/Centro de Ensino Superior do Seridó, Universidade Federal do Rio Grande do Norte, jucyelho@hotmail.com

Eixo: Uso e ocupação das terras e legislação ambiental

\begin{abstract}
Resumo
Dentre os diversos fatores que se encontra em crescimento em Caicó/RN, destaca-se a questão dos impactos ambientais negativos causados pelo lixão irregular da cidade. Através de pesquisas bibliográficas, aquisições de dados geoespaciais e técnicas de geoprocessamento foi possível observar, delimitar e quantificar os impactos ocasionados pela inadequação da destinação final dos resíduos sólidos do município tendo como parâmetro principalmente o Art. 47 da lei $\mathrm{n}^{\circ}$ 13.305/2010. O objetivo geral da pesquisa é realizar uma análise nas atuais condições do lixão, averiguando se o mesmo está em acordo com lei, e também identificar os impactos ambientais negativos decorrentes destas irregularidades. De acordo com observações em campo foram vistos impactos provenientes do lixão em um raio de aproximadamente $210 \mathrm{~m}$. Desta forma conclui-se que, as condições do lixão estão em desacordo com a lei e gerando consequentemente impactos ambientais negativos.
\end{abstract}

Palavras chave: Caicó; Impacto ambiental; Lixão.

\section{Introdução}

A cidade de Caicó, interior do estado do Rio Grande do Norte, está localizada na microrregião Seridó

Ocidental. A área de estudo, local de disposição final dos resíduos sólidos da cidade, está localizada nos limites da cidade de Caicó/RN (Figura 1), mais precisamente no sítio Várzea Redonda, na margem direita da BR-427. 


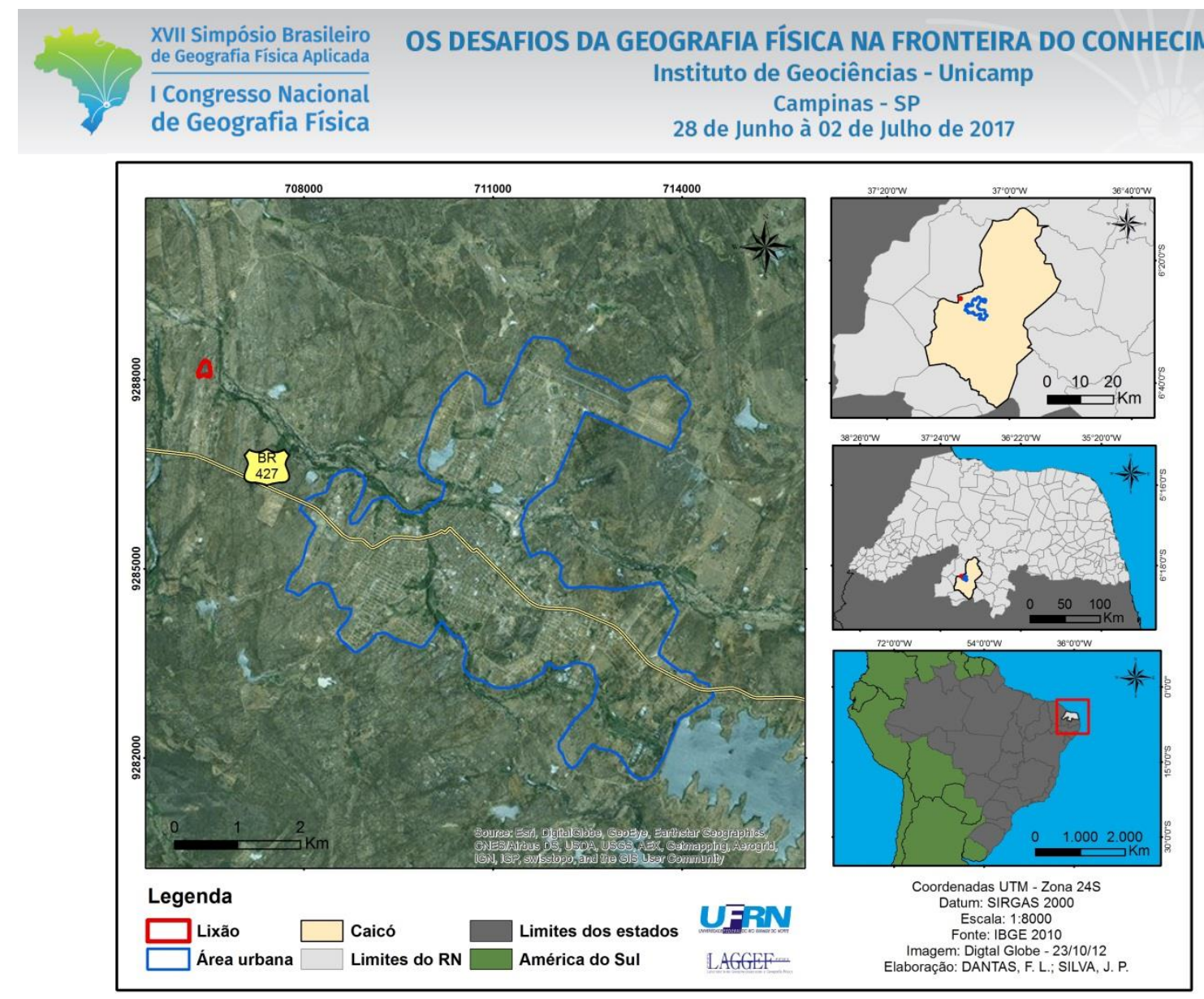

Figura 01 - Mapa de Localização do depósito de Resíduos Sólidos de Caicó/RN, 2017.

Segundo Santos (2004) apud Batista et al. (2010) a forma do impacto, fonte, sentido, distribuição, extensão, desencadeamento, temporalidade, intensidade, reversibilidade, frequência, acumulação e magnitude são critérios extremamente úteis na classificação dos impactos ambientais.

Dentre os diversos fatores que se encontra em constante crescimento no município, destaca-se a questão dos impactos ambientais negativos que o lixão, com seu armazenamento irregular a céu aberto e acumulo excessivo de resíduos, provoca em suas proximidades, seja alterando na qualidade do solo, dos corpos hídricos ou do ar. Esta pesquisa tem como objetivo averiguar se as condições do lixão localizado na cidade de Caicó/RN estão em acordo com o Art. 47 da lei no 12.305/2010 que proíbe lançamento de resíduos em quaisquer corpos hídricos, lançamento de resíduos in natura a céu aberto e queima de resíduos a céu aberto.

\section{Metodologia}

Para a execução deste trabalho foram feitas pesquisas bibliográficas a respeito do lixão da cidade de Caicó, sobre a Política Nacional de Resíduos Sólidos principalmente do que diz respeito ao capítulo VI das proibições, no Art. 47 (BRASIL, 2010), no qual diz que "São proibidas as seguintes formas de 
destinação ou disposição final de resíduos sólidos ou rejeitos: I - lançamentos em praias, no mar ou em quaisquer corpos hídricos; II - lançamento in natura a céu aberto, excetuados os resíduos de mineração; III - queima a céu aberto ou em recipientes, instalações e equipamentos não licenciados para essa finalidade; IV - outras formas vedadas pelo poder público." E também analisar os impactos ambientais negativos decorrentes destas irregularidades.

Em seguida foi feito uma busca por dados geoespaciais da área de estudo, no qual foram obtidos arquivos matriciais do tipo foto com resolução espacial de 1,3m do Google Earth Pro e imagens do tipo raster, com resolução espacial de 30m, do MDE da região (Modelo Digital de Elevação) obtidas na Shuttle Radar Topography Mission - SRTM e disponibilizado pelo USGS Serviços geológico americano (United States Geological Survey) no portal do Earth Explorer. Além destes foram obtidos arquivos vetoriais da Base Cartográfica do IBGE 2013, na escala 1:250.000 - BC250.

Com os dados do SRTM foi feito um pós-processamento para transformar o raster de $30 \mathrm{~m}$ em um raster de resolução espacial de $8,7 \mathrm{~m}$ para resolver o problema de pixel estourado devido à área de estudo ser muito pequena a qual requer um zoom muito grande, portanto, esse procedimento se deu através da transformação do MDE em shapefile de pontos cotados e feito uma interpolação dos pontos através do método Natural Neighbor (Vizinho natural) e posteriormente transformado novamente em arquivo matricial de resolução $8,7 \mathrm{~m}$ valor este gerado automaticamente pelo software utilizado que foi o ArcGis 10.4. Com esses dados foi gerado o mapa de situação 1 em conjunto com as informações da direção dos ventos predominantes obtidos no BDMAP, dados históricos, do INMET.

Com os arquivos vetoriais foram feitos os recortes da área de interesse para estudo e posteriormente o mapa de localização, em conjunto com a imagem obtida do Google Earth Pro.

A partir desses resultados foi-se a campo utilizando um GPS de navegação da Garmin modelo Montana 680 e câmera fotográfica da Canon de $12 \mathrm{mp}$, para fazer checagem dos pré-resultados e registros e medições para o mapa de situação 2 .

Com os dados obtidos, analisados, processados e checados em campo foram desenvolvidos os resultados, considerações finais e a transcrição deste trabalho.

\section{Resultados e discussões}

Segundo o Conselho Nacional do Meio Ambiente - CONAMA, impacto ambiental é qualquer alteração das propriedades físicas, químicas e biológicas do meio ambiente, causada por qualquer forma de matéria ou energia resultante das atividades humanas que, direta ou indiretamente, afetam: a saúde, a segurança e 


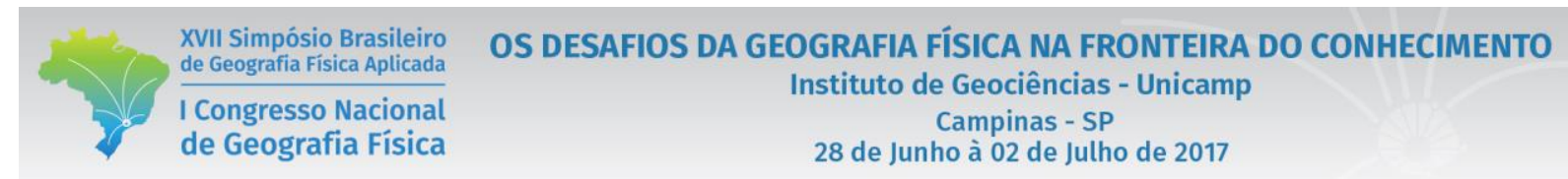

o bem-estar da população; as atividades sociais e econômicas; a biota; as condições estéticas e sanitárias do meio ambiente; e a qualidade dos recursos ambientais.

A avaliação do impacto significa a interpretação qualitativa e quantitativa das mudanças, de ordem ecológica, social, cultural ou estética. (Batista et al., p.02, 2010) A área do lixão encontra-se desprovida de manutenção, monitoramento e sem fiscalização, caracterizando-se em grave perturbação do meio ambiente.

No mais, de acordo com o mapa de situação 01 (figura 02) percebe-se que o local escolhido para a destinação final dos resíduos sólidos desta cidade foi feita sem nenhum planejamento, pois o lixão encontra-se entre dois rios e em uma área mais alta que seu entorno deixando-se assim mais susceptível à ação eólica e a ação da gravidade que em conjunto a pluviosidade potencializa a degradação do meio ambiente no seu entorno.

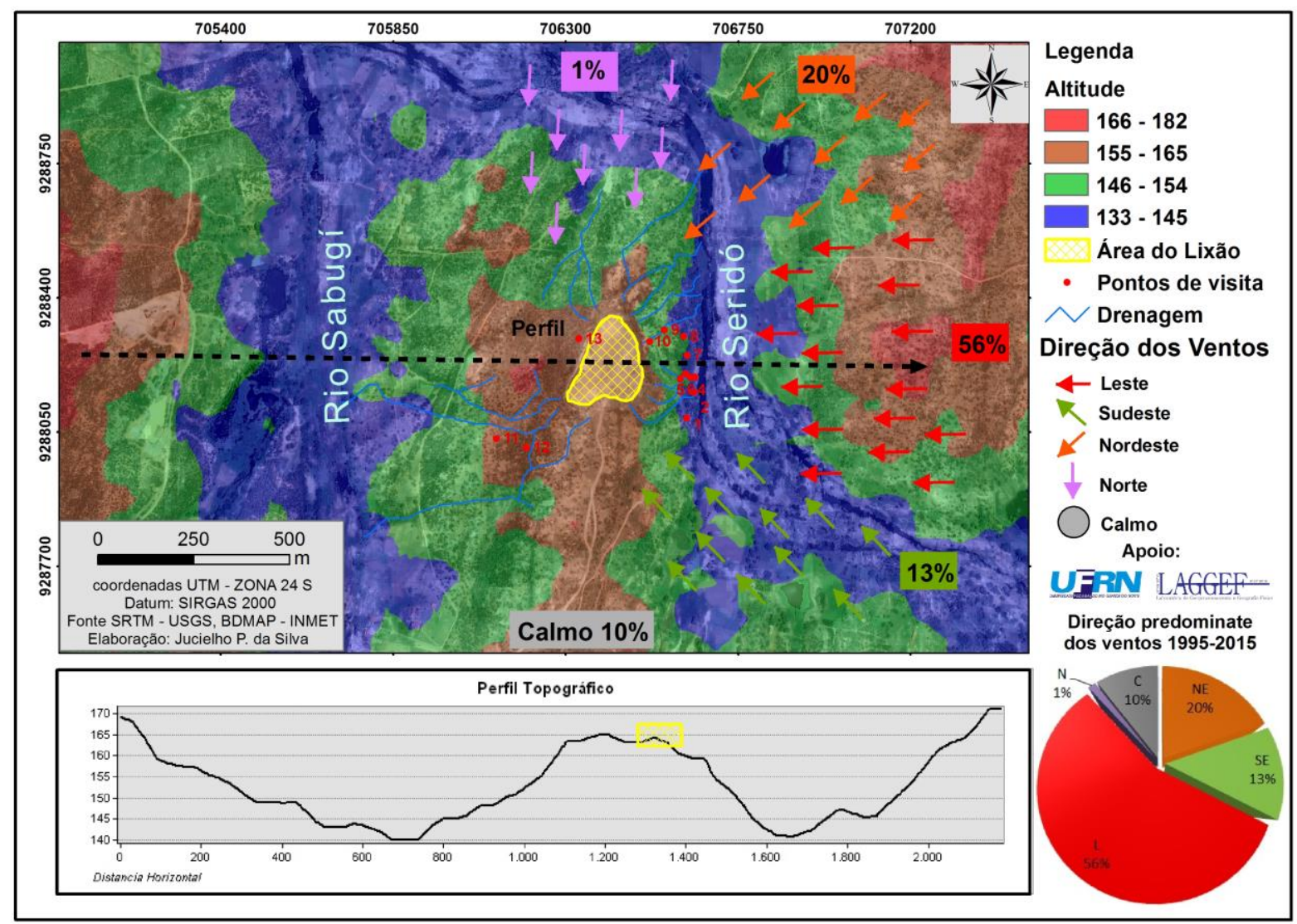

Figura 02 - Mapa de situação 1

Como pode ser visto no mapa de situação 1, o local escolhido para a deposição dos resíduos encontra-se nas cotas altimétricas mais elevadas e seu entorno encontra-se em cotas menos elevadas como pode ser percebido também no perfil topográfico, dessa forma por ação da gravidade e ação hidrológica esses 


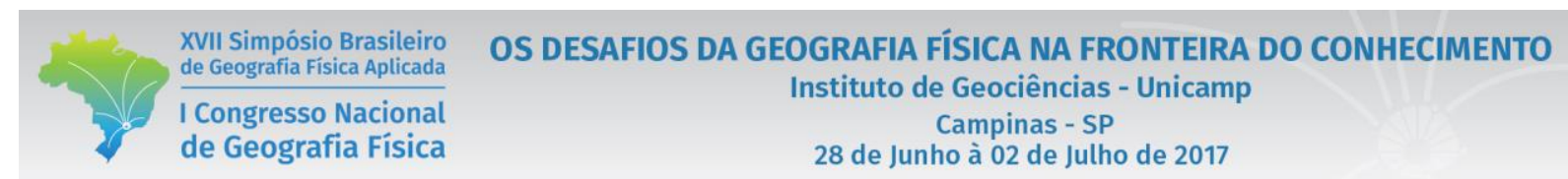

dejetos tendem a se espalhar e migar para as áreas adjacentes gerando impactos ambientais principalmente na vegetação e nos corpos hídricos que segundo Silva, Pereira e Azevedo (2015) o local de deposito fica a 150m do leito principal do rio Seridó e a 690m do rio Sabugí.

Por esse local de deposição dos resíduos estarem em uma área mais elevada, fica também mais propicio ao espalhamento devido à ação eólica que de acordo com os dados de direção dos ventos dos anos de 1995 a 2015 que podem ser vistos em forma de gráfico de pizza na figura 02, e traduzido em setas na figura em analise, as regiões dos setores Oeste, Sudeste, Sudoeste e Sul tendem ter um impacto maior devido os ventos predominantes que vem de Leste, Nordeste, Sudeste e Norte respectivamente. Estes impactos diferenciais podem ser melhores compreendidos na (figura 03) Mapa de situação 2.

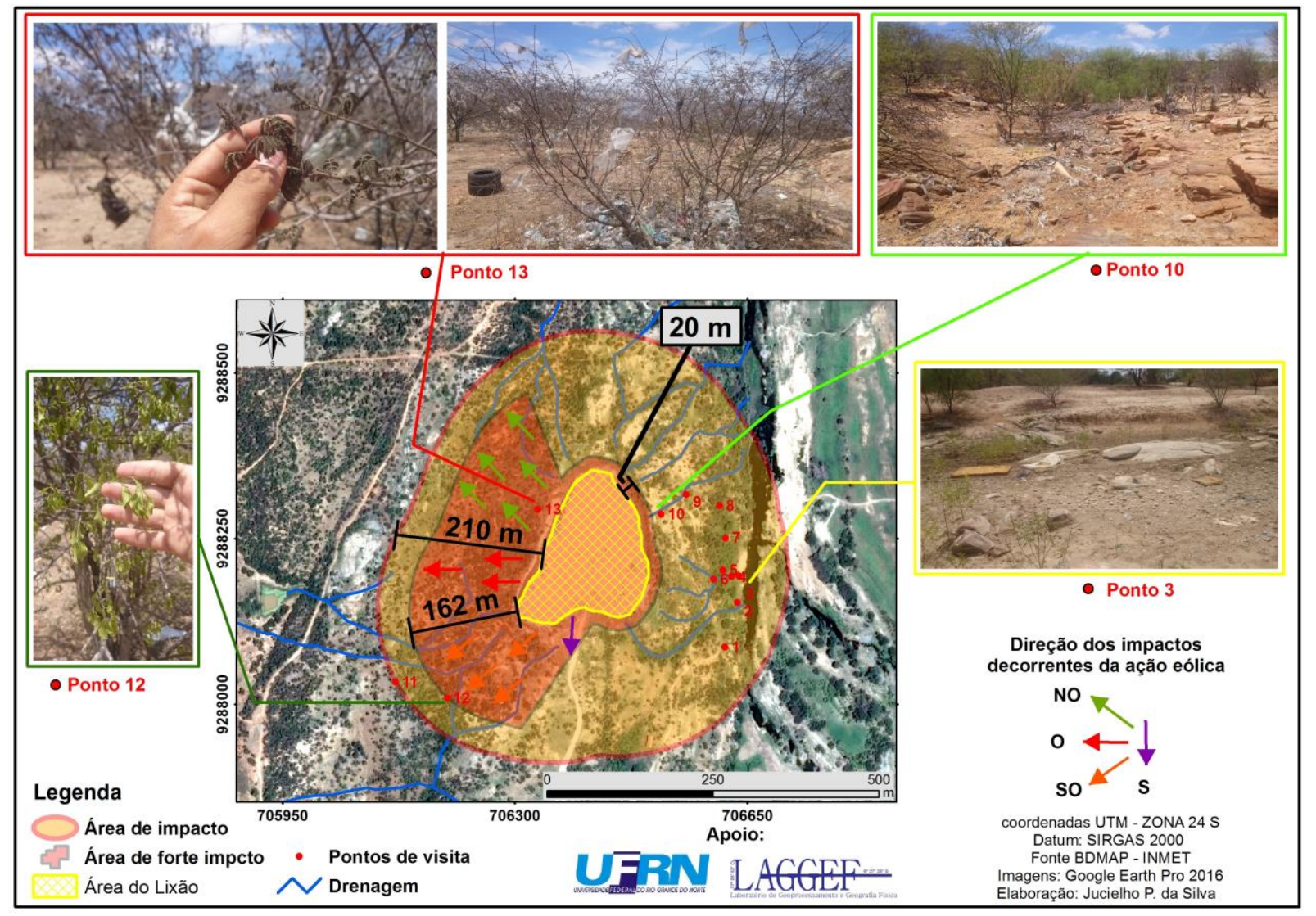

Figura 03 - Mapa de situação 2

De acordo com observações em campo e representado nesta figura 03, foram avistados dejetos provenientes do lixão em um raio de aproximadamente $210 \mathrm{~m}$, sendo que foi encontrado em maior quantidade num raio de $20 \mathrm{~m}$ em todo seu entorno devido à ação da gravidade e ventos gerados localmente, e em um raio de aproximadamente $162 \mathrm{~m}$ nos sentido Oeste, Sudeste, Sudoeste e Sul devido à predominância dos ventos que atua na região. 


\section{OS DESAFIOS DA GEOGRAFIA FÍSICA NA FRONTEIRA DO CONHECIMENTO \\ Instituto de Geociências - Unicamp \\ Campinas - SP \\ 28 de Junho à 02 de Julho de 2017}

Como pode ser visto nas fotos da figura 03, na região oriental da área de impactos, há uma maior ocorrência de degradação gerada pela ação da gravidade e pela ação hidrológica, devido esse lado ser mais íngreme e não sofrer tanta influência dos ventos. No ponto 3 foi visto lixo dentro da calha principal do rio Seridó seco no período de estiagem, no ponto 10 foi encontrado um córrego que ligava o lixão ao rio e nele seguia uma trilha de lixo em todo o percurso o que comprovou a ação hidrológica carregando o lixo até o rio.

$\mathrm{Na}$ região ocidental da área de impactos, foi observada uma degradação mais intensa do que na região oposta, pois além da ação da gravidade e hidrológica observou-se a atuação da expressiva ação dos ventos predominantes de leste, desta forma foi denominado de área de fortes impactos, nesta região foi visto dejetos carregados pela ação eólica até aproximadamente $162 \mathrm{~m}$ e dejetos carregados pela ação hidrológica até os $210 \mathrm{~m}$. Deste lado foi visto muitos sacos plásticos e cinzas nas presas a vegetação diminuindo-o, provavelmente, a capacidade de fotossíntese das mesmas, como pode ser visto no ponto 13, do ponto 12 ao 11 não foi observado mais a impactos expressivos da ação eólica, apenas resquícios de dejetos carregados pela ação hidrológica.

Segundo Dueñas et al. (2003), o lixo, disposto inadequadamente, sem qualquer tratamento, altera suas características físicas, químicas e biológicas, gerando contaminações diretas e/ou indiretas, potencializando a vulnerabilidade do ambiente natural.

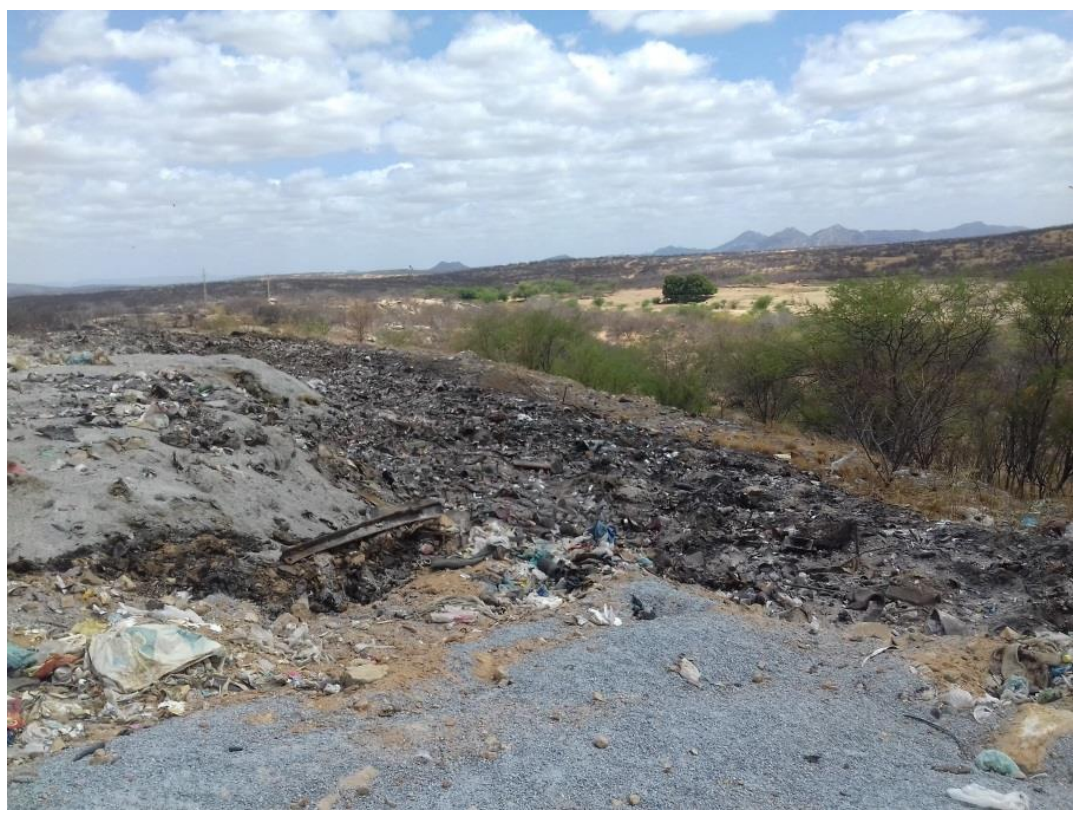

Figura 4 - Imagem dos resíduos queimados a céu aberto. 


\section{OS DESAFIOS DA GEOGRAFIA FÍSICA NA FRONTEIRA DO CONHECIMENTO \\ Instituto de Geociências - Unicamp \\ Campinas - SP \\ 28 de Junho à 02 de Julho de 2017}

Foi identificada também a execução de queimadas dos resíduos a céu aberto (Figura 4), emitindo grandes quantidades de fumaça na atmosfera e com a ação eólica o mesmo sendo levado para uma área urbana próxima, que é a cidade de São Fernando, representando um risco ambiental e para a saúde pública.

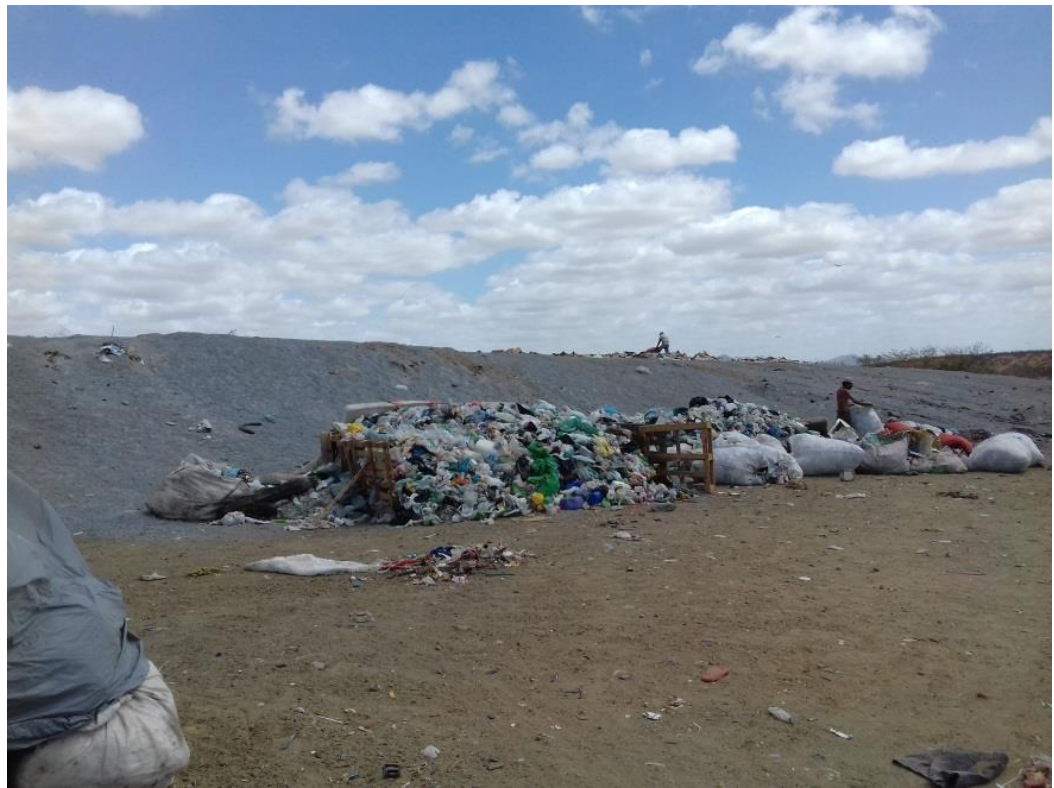

Figura 5 - Imagem do processo de aterramento.

Decorrente da impossibilidade de cessar as queimadas é feito o processo de abafamento irregular com aterro. Este processo de aterramento sem planejamento também é usado para colocar sobre os resíduos e obter mais espaço para depositar mais lixo (Figura 5), e a consequência deste método é não ter o conhecimento se o fogo cessou ou se ele continua queimando internamente, possibilitando o acúmulo de gases inflamáveis no interior deste aterramento, gerando-se assim um risco gravíssimo de explosões.

\section{Considerações finais}

Conclui-se que, as condições ambientais do lixão estão em desacordo com o Art. 47 da lei no 12.305/2010, e apresenta também a falta de responsabilidade da administração municipal de Caicó/RN para manter o lixão fiscalizado e de acordo com as leis vigentes. Nota-se a necessidade de um Plano de Resíduos Sólidos Municipal para haver uma boa gestão das demandas ambientais e das práticas sustentáveis. Acredita-se também a necessidade de estudos e pesquisas relacionadas à gestão de resíduos sólidos urbanos e proteção ambiental. 


\section{Bibliografia}

BATISTA, D. M. B.; SILVA, J. M. N.; SOUSA, E. F.; Ó, L. G. D.; BARBOSA, E. A. B. O uso do método da listagem de controle na identificação de impactos ambientais negativos: o caso do lixão de uma cidade de médio porte. In: XXX ENCONTRO NACIONAL DE ENGENHARIA DE PRODUÇÃO, 2010, São Carlos, Anais... São Carlos: UFSCar, 2010.

BRASIL. Lei 12.305, de 2 de agosto de 2010. Institui a Política Nacional de Resíduos Sólidos, altera a Lei 9.605 e dá outras providências. Disponível em: http://www.mma.gov.br/port/conama/legiabre.cfm?codlegi=636. Acesso em: 07/out/2016.

BRASIL. Resolução Conama $\mathbf{N}^{\mathbf{0}}$ 001, de 23 de janeiro de 1986 . Disponível em: http://www.mma.gov.br/port/conama/res/res86/res0186.html. Acesso em: 08/fev/2017.

DUEÑAS, M. A. F.; CÂMARA, A. R.; ROCHA, B. O.; MACHADO, C. E. O impacto do "lixão" na qualidade de vida da comunidade circunvizinha nos bairros de Cidade Nova e Felipe Camarão - Natal/RN. XXIII ENCONTRO NACIONAL DE ENGENHARIA DE PRODUÇÃO, 2003, Ouro Preto, Anais... Outo Preto: 2003.

INSTITUTO NACIONAL DE METEOROLOGIA. Banco de dados meteorológicos para ensino e pesquisa. Disponível em: http://www.inmet.gov.br/portal/index.php?r=bdmep/bdmep. Acesso em: 01/mar/2017.

SILVA, J. P.; PEREIRA, V. H. C., AZEVEDO, J. M.. Análise do meio físico como subsídio para indicação de método de aterro sanitário para o município de Caicó/RN. In: XVI SIMPÓSIO BRASILEIRO DE GEOGRAFIA FÍSICA APLICADA, 2015, Teresina, Anais eletrônicos... Teresina: UFPI, 2015. Disponível em: http://www.sbgfa.ggf.br/2015/. Acesso em: 09/nov/2016.

USGS - United States Geological Survey. Earth Explorer. Disponível em: https://earthexplorer.usgs.gov/. Acesso em: 01/mar/2017. 